\title{
The Development and Characterization of a pH Dependent Matrix Tablet Containing Probiotics
}

\author{
Seong-Wan Cho ${ }^{1}$ and Young-Kwon Kim ${ }^{2, \dagger}$ \\ ${ }^{I}$ Department of Pharmaceutics \& Biotechnology, Konyang University, Daejeon 35365, Korea \\ ${ }^{2}$ Department of Biomedical Laboratory Science, Konyang University, Daejeon 35365, Korea
}

The objective of this study was to develop a $\mathrm{pH}$ dependent oral matrix tablet containing probiotics. In this study, hydroxyl-propyl-methyl-cellulose (HPMC) and polyvinyl pyrrolidone K30 (PVP K-30) was utilized as a binder, sodium starch glycolate (SSG) was used as a disintegrant material for the tablet formulation. The disintegration test, hardness test, angle of response were performed to examine the characteristics of prepared tablet. Lactobacillus vitality test was applied to analyze the total Lactobacillus viable count. The results demonstrated that the $\mathrm{pH}$ dependent matrix tablet was prepared successfully and can thus be industrialized instead of the current methodologies used for preparation of conventional probiotics.

Key Words: Probiotics, pH-dependent, Matrix, Tablet, Lactobacillus plantarum

\section{서 론}

최근 현대인들의 불규칙하고 좋지 않은 식습관으로 인 해 스트레스와 변비, 설사 등과 같은 소화불량을 일으키 는 사람들이 증가하고 있다. 이러한 소화불량을 해결하기 위해 대부분의 사람들이 사용하는 방법은 소화제를 복용 하는 것이지만 이는 임시방편일 뿐으로 장 건강을 계속 적으로 개선할 수는 없으며 근본적인 해결책으로 최근에 제안되는 방법은 장의 환경을 바꾸어 주기 위해 프로바이 오틱스(probiotics)를 이용하는 방법이다. 프로바이오틱스란 체내에서 인체에 유용성을 제공하는 유익균을 의미하는데 러시아의 과학자 Elie Mechinikoff가 불가리아에 장수하는 사람들이 많은 이유가 Lactobacillus로 발효된 발효유의 섭 취 때문인 것을 밝혀내어 노벨상을 수상한 이래로 그 효
능은 최근까지 계속 연구되어 오고 있다(Fuller, 1991; Kim and Gilliland, 1983; McFarland et al., 1995; Hove et al., 1999; Nguyen et al., 2007). 하지만 이러한 유익성에도 불구하고 프로바이오틱스는 다음과 같은 단점을 가지고 있어 그 효과가 극대화 되기 쉽지 않다는 많은 연구들이 보고되고 있는 데 즉, 복용했을 때 $\mathrm{pH} 3$ 이하의 산성 환경인 위장 에서 그 활성을 대부분 잃으며, 소화 효소 및 담즙산에도 영향을 받아 장내 정착률이 저하되어 유산균의 생존율 유 지가 복용의 성패를 좌우하는 매우 중요한 인자가 된다는 것이다(Berrada et al., 1991; Bouhnik et al., 1992; Marteau et al., 1993; Cross et al., 2002; De Moreno de LeBlanc et al., 2008).

이러한 프로바이오틱스의 문제점들을 보완하기 위해 사 용하는 제제학적 기술은 유산균 원말 자체를 장용 코팅하 거나 유산균을 장용성 코팅이 되어 있는 캡슐에 충진하여 유산균의 생존률을 증가시키는 것이다. 이러한 기술들은

\footnotetext{
* Received: September 27, 2016 / Revised: December 3, 2016 / Accepted: December 6, 2016

${ }^{\dagger}$ Corresponding author: Young-Kwon Kim. Department of Biomedical Laboratory Science, Konyang University, Gwanjeodong-ro, Seo-gu, Daejeon 35365, Korea.

Tel: +82-42-600-6371, Fax:+82-42-600-1641, e-mail: ykkim3245@konyang.ac.kr

(C) The Korean Society for Biomedical Laboratory Sciences. All rights reserved.

(C) This is an Open Access article distributed under the terms of the Creative Commons Attribution Non-Commercial License (http://creativecommons.org/licenses/by-nc/3.0/) which permits unrestricted non-commercial use, distribution, and reproduction in any medium, provided the original work is properly cited.
} 
프로바이오틱스의 생존률을 어느 정도 증대시킬 수 있다 고 알려져 현재까지 계속 사용되어 왔지만 또 다른 문제 점을 가지고 있다는 것이 최근 밝혀져 문제가 되고 있다. 즉, 캡슐제의 경우는 캡슐제 피막조성의 대부분이 젤라틴 으로 이루어져 있기 때문에 젤라틴 특유의 이상한 냄새와 피막이 위산에 분해되어 팽윤되면서 유상의 내용물이 위 장으로 용출되면서 느껴질 수 있는 거부감 등이 문제가 될 수 있으며 장용성 코팅의 경우는 장용성 코팅기제로 일반적으로 사용하는 프탈산 히드록시 프로필 메틸셀룰로 오스(HPMCP)에 포함된 프탈레이트가 암을 유발하며, 태 아사망, 기형, 고환 및 간 손상, 과산화물질 증대를 발생 시킬 수 있는 내분비교란물질로서 알려져 있다는 것이다 (Peck et al., 2011; Abdel and Aiman, 2012).

본 연구에서는 $\mathrm{pH}$ 에 취약한 유산균을 위액과 담즙산으 로 보호하며, 장에서 유산균이 용출될 수 있는 $\mathrm{pH}$ 의존성 매트릭스 정제를 개발함으로써 기존 제제 기술들의 단점 을 개선하고 제형의 다양성을 확보하려 하였으며 또한 점 성을 가지는 고분자를 통해 장내 부착율을 높임으로서 지 속성을 유지할 수 있는 제제를 개발하고자 하였다.

\section{재료 및 방법}

\section{정제의 제조}

프로바이오틱스는 식품의약품안전처로부터 일일 섭취 량이 이미 규정되어 있으며, 유산균 증식 및 유해균 억제, 배변활동 원활에 도움을 주는 것으로 기능성이 입증되어 있으므로 본 연구에서는 그 기준에 맞추어 주성분인 프로 바이오틱스 함유량을 기능성의 범위인 1 정당 $600 \mathrm{mg}$ 이 되도록 제조하였다. 정제의 제조 방법은 습식 과립 제조 방법에 따라 제조하였는데 부형제와 주원료, 그리고 결합 제를 혼합하여 과립을 제조한 후 건조하고 타정을 실시하 여 정제를 제조하였으며 코팅액은 따로 코팅기제를 물과 에탄올에 용해시켜 조제하고 코팅 공정을 실시하였다. 코 팅 공정 시 건조 온도에 의한 프로바이오틱스의 사멸을 최소화하기 위하여 product temperature는 $40^{\circ} \mathrm{C}$ 이하로 진 행하였으며 warming-up temp $55^{\circ} \mathrm{C}$, warming-up time $5 \mathrm{~min}$, inlet temp $55^{\circ} \mathrm{C}$, exhaust temp $36^{\circ} \mathrm{C}$, product temp $36^{\circ} \mathrm{C}$ 로 설 정해 장용성 코팅을 하였다.

\section{장용성 정제의 경도 및 붕해 시험}

장용성 정제를 제조한 후에는 붕해 정도를 알아보기 위 하여 붕해 시험기(Disintegration tester, Kukje Engineering Co.,
Seoul, Korea)를 이용하여 붕해 시험을 실시하였다(Doh et al., 2002; Korean Food and Drug Administration, 2011). 붕 해 시험 평가 방법은 장용성 코팅 정제를 인공위액 $(\mathrm{pH} 1.2$ 액)과 인공장액(pH 6.8 액)에 6정씩 넣은 다음, 인공위액은 120 분, 인공장액은 60 분간 상하운동을 한 다음 관찰하여 코팅피막 용해 정도와 정제의 붕해 양상을 육안으로 관찰 하였다. 인공위액은 염화 나트륨 $2.0 \mathrm{~g}$ 과 염산 $7.0 \mathrm{~mL}$ 을 물에 녹여 $1,000 \mathrm{~mL}$ 로 하고 $\mathrm{pH}$ 는 약 1.2 로 맞추었으며 $\mathrm{pH} 6.8$ 액은 $0.2 \mathrm{~mol} / \mathrm{L}$ 인산이수소칼륨시액 $250 \mathrm{~mL}$ 에 0.2 $\mathrm{mol} / \mathrm{L}$ 수산화나트륨시액 $118 \mathrm{~mL}$ 및 물을 넣어 $\mathrm{pH}$ 는 약 6.8 로 만들었다. 상기 붕해 시험 조건에 따라 $37 \pm 2^{\circ} \mathrm{C}$ 의 온도에서 분당 29 32회의 속도로 상하운동을 시켰으며 각 액에서 규정하는 붕해 시간 이후 붕해 시험기 유리관 에 시료의 잔류물이 없거나 있더라도 피막이든가 연질의 물질 또는 니상의 물질이 잔류할 경우 적합으로 하였다. 또한 제조된 정제의 경도 실험은 경도계(Hardness Tester, Labotech., Seoul, Korea)를 사용하여, 마손의 정도는 마손도 기(Friabilator, Kukje Engineering Co., Seoul, Korea)를 이용하 여 제조된 정제의 특성을 평가하였다.

\section{유산균 활성 시험}

제조된 프로바이오틱스 정제 및 유산균 원말을 생리식 염수 또는 인산 완충액(Phosphate-buffer)에 현탁한 후 희 석하고 고체 배지(agar plate)에 도말하여 생존 유산균의 수를 계수하였다. 평가된 정제와 유산균 활성을 비교하 기 위하여 비교 대상으로는 유산균 원말을 사용하였으며 Lactobacillus plantarum 검출 배지인 Lactobacilli $\mathrm{MRS}(\mathrm{BD}$, 288130)와 Bifidobacterium bifidum 검출 배지인 BL (MBcell, MB-B1602)을 사용하여 마찬가지로 그 활성의 정도를 측 정하여 보았다. 각각의 시료들은 샘플 중량에 따라 600 $\mathrm{mg}$ 을 각각 취하여 MRS broth(액체 배지)를 각 중량의 4 배를 넣어 $1 / 5$ 로 희석하여 1 시간 정도 vortex하여 균질화 하였으며 희석된 각각의 시료들을 원액으로 하여 $10^{-7}$ 까 지 serial dilution하여 MRS 평판 배지와 $\mathrm{BL}$ 평판 배지에 $100 \mu 1$ 씩 도말하여 $37^{\circ} \mathrm{C}$ incubator에서 3일 정도 배양하였 다. Lactobacillus 검출 배지인 MRS 평판배지는 aerobic (호 기) condition으로, Bifidobacterium 검출 배지인 $\mathrm{BL}$ 평판 배 지는 anaerobic(혐기, gas pack 사용한 후 진공 sealing) condition으로 배양하여 정제 제조 전후의 유산균 활성도를 비교하여 보았다(Ferreira et al., 2005; Kim et al., 2015, Hong et al., 2015; Hong and Lee, 2015). 
Table 1. The formulation of $\mathrm{pH}$ dependent matrix tablet containing probiotics

\begin{tabular}{llcrrrrr}
\hline \hline & \multicolumn{1}{c}{ Formulation $(\mathrm{mg})$} & 1 & 2 & 3 & 4 & 5 & 6 \\
\hline $\begin{array}{l}\text { Active pharmaceutical } \\
\text { ingredient }\end{array}$ & $\begin{array}{l}\text { Probiotics } \\
\text { (Lactobacillus plantarum) }\end{array}$ & $500 \mathrm{mg}$ & $500 \mathrm{mg}$ & $500 \mathrm{mg}$ & $500 \mathrm{mg}$ & $500 \mathrm{mg}$ & $500 \mathrm{mg}$ \\
Binder & Hydroxy propyl methyl cellulose & $30 \mathrm{mg}$ & - & $30 \mathrm{mg}$ & $30 \mathrm{mg}$ & $30 \mathrm{mg}$ & $30 \mathrm{mg}$ \\
Disintegrant & Sodium starch glycolate & - & $20 \mathrm{mg}$ & - & $20 \mathrm{mg}$ & - & $20 \mathrm{mg}$ \\
Binder & Polyvinyl pyrrolidone K30 & - & - & $20 \mathrm{mg}$ & $20 \mathrm{mg}$ & $40 \mathrm{mg}$ & $40 \mathrm{mg}$ \\
Glydent & Magnesium stearate & $6 \mathrm{mg}$ & $6 \mathrm{mg}$ & $6 \mathrm{mg}$ & $6 \mathrm{mg}$ & $6 \mathrm{mg}$ & $6 \mathrm{mg}$ \\
Coating materials & Hydroxy-propyl-cellulose & $12 \mathrm{mg}$ & $12 \mathrm{mg}$ & $12 \mathrm{mg}$ & $12 \mathrm{mg}$ & $12 \mathrm{mg}$ & $12 \mathrm{mg}$ \\
Coating materials & Sodium alginate composition & $24 \mathrm{mg}$ & $24 \mathrm{mg}$ & $24 \mathrm{mg}$ & $24 \mathrm{mg}$ & $24 \mathrm{mg}$ & $24 \mathrm{mg}$ \\
\hline
\end{tabular}

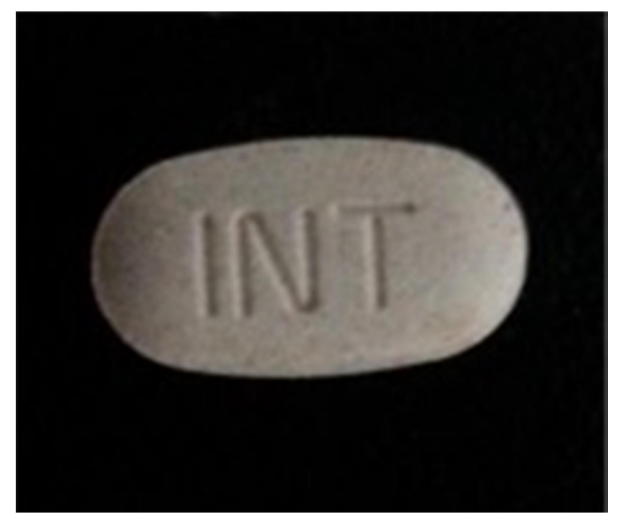

Fig. 1. The picture of prepared $\mathrm{pH}$ dependent matrix tablet.

\section{결 과}

\section{$\mathrm{pH}$ 의존성 매트릭스 유산균 정제의 제조}

실험을 통하여 확정된 $\mathrm{pH}$ 의존성 matrix tablet의 원료약 품 최종 배합 및 분량은 Table 1 과 같으며 이 중에서도 가장 정제 제조가 잘되는 6 번을 최종 처방으로 선택하였 다. 완성된 정제의 사진은 Fig. 1과 같은데 이때 정제를 제 조하기 위하여 사용된 결합제로는 hydroxyl-propyl-methylcellulose (HPMC)와 Polyvinyl pyrrolidone (PVP) K30 이었 으며 붕해제로는 sodium starch glycolate (SSG)를, 활택제 로는 magnesium stearate임을 알 수 있었다. 코팅기제로는 hydroxyl-propyl-cellulose와 sodium alginate composition을 혼 합하여 사용하는 것이 가장 장용 코팅이 잘 된다는 것을 확인할 수 있었다.

\section{$\mathrm{pH}$ 의존성 매트릭스 유산균 정제의 특성 평가}

제조된 $\mathrm{pH}$ 의존성 매트릭스 정제의 특성 평가를 위
Table 2. The characteristics of $\mathrm{pH}$ dependent matrix tablet containing probiotics

\begin{tabular}{lcc}
\hline \hline & Criterion & Results \\
\hline Disintegration test & $<20 \mathrm{~min}$ & $5 \mathrm{~min} 30 \mathrm{sec}$. \\
Hardness test & $>7 \mathrm{kp}$ & $8 \mathrm{kp}$ \\
Friability test & $<0.5 \%$ & $0.25 \%$ \\
Angle of response & $<40^{\circ}$ & $32^{\circ}$ \\
\hline
\end{tabular}

Table 3. Lactobacillus vitality test of $\mathrm{pH}$ dependent matrix tablet containing probiotics

\begin{tabular}{lcc}
\hline \hline & Mix & Tablet \\
\hline MRS & $1.7 \times 10^{10} \mathrm{CFU} /$ Tablet & $7.0 \times 10^{9} \mathrm{CFU} /$ Tablet \\
BL & $1.8 \times 10^{10} \mathrm{CFU} /$ Tablet & $7.5 \times 10^{9} \mathrm{CFU} /$ Tablet \\
\hline
\end{tabular}

하여 경도 및 붕해 시험을 실시하여 본 결과는 Table 2 와 같았다. 제조된 정제는 미황색을 띤 정제로서 붕해기 (Disintegration tester)를 이용하여 측정한 붕해 시간은 약 5 분 30 초에 진행되어 정제의 경우는 20 분 이내에 붕해되 어야 하는 기준을 만족하였으며 경도는 $8 \mathrm{kp}$ 로서 장용성 코팅에 필요한 $7 \mathrm{kp}$ 이상의 경도를 만족시켜 코팅이 성공 적으로 진행이 가능하였다. 또한, 마손도 시험(Friability test)과 안식각 시험(angle of response test)도 기준에 만족 하여 성공적으로 정제가 제조되었음을 확인할 수 있었다 (Table 2).

\section{유산균 활성 시험}

프로바이오틱스 혼합물의 유산균 배양 시험에서 $\mathrm{MRS}$ 배지의 경우에는 혼합물의 경우 $1.7 \times 10^{10} \mathrm{CFU} / 600 \mathrm{mg}$ 를, 정제의 경우 $7.0 \times 10^{9} \mathrm{CFU} / 600 \mathrm{mg}$ 를 나타내었으며 $\mathrm{BL}$ 배 
지에서도 혼합물의 경우 $1.8 \times 10^{10} \mathrm{CFU} / 600 \mathrm{mg}$ 를, 정제의 경우 $7.5 \times 10^{9} \mathrm{CFU} / 600 \mathrm{mg}$ 를 나타내었다. 식품 의약품 안전처의 식품 안전 정보 포털에 따르면 기능 성분의 함 량은 프로바이오틱스균을 $1 \times 10^{8} \mathrm{CFU} / \mathrm{g}$ 이상 함유하고 있 으면 최종제품의 요건으로 유산균 증식 및 유해균 억제, 배변활동 원활에 도움을 줄 수 있는 것으로 되어 있으므 로 제조된 정제는 그 기능성을 유지한 채로 성공적으로 제품이 제조되었다는 것을 확인할 수 있었다. 이러한 결 과를 통해 본 연구에서 정제를 제조하기 위해 사용한 매 트릭스 기법이 프로바이오틱스의 안정성을 확보할 수 있 는 효과적인 정제 제형의 기술이라는 것을 알 수 있었다 (Table 3).

\section{고 찰}

본 연구에서는 유산균 제제의 안정성 확보를 위하여 유 산균 식품의 제조에 일반적으로 사용되는 장용 코팅 또는 캡슐 충전의 방법 대신에 $\mathrm{pH}$ 의존성 matrix 정제를 제조 하여 산성 환경인 위장과 소장에서 분비되는 많은 소화 효소에서도 생균 수의 안정성을 확보할 수 있는 기술을 개발하고자 하였다. 본 연구에 사용된 매트릭스(matrix) 제 형화 기술은 비활성 고분자 매트릭스 중에 주성분인 약 물이 균일하게 분산되어 방출 혹은 침식 속도를 조절하 는 시스템으로 매트릭스 시스템의 장점은 유산균 원말을 코팅하는 것보다 제조 공정에서 바로 적용이 가능하므로 생산공정 단축 및 원가절감과 수율 향상이 가능하며 또 한 정제로 제형화 하는 것이 캡슐제에 비해 제조원가가 절감되므로, 제조사에게 이득이 되는 제조 기법이 될 수 있다는 것이다(Cui et al., 2002). 매트릭스 기술을 도입하여 정제를 제조하고 [대한약전 9개정]과 [경구용의약품의 용 출규격 설정 가이드라인]과 [건강기능식품이 기준 및 규 격 고시전문]의 붕해 시험법에 근거하여 유산균 정제의 특성 및 거동을 확인하여 본 결과 붕해가 원활하여 성공 적으로 유산균 정제가 제조되었음을 확인할 수 있었으며 이러한 결과를 바탕으로 $\mathrm{pH}$ 에 취약한 프로바이오틱스를 위액과 담즙산으로 보호하며, 장에서 프로바이오틱스가 용 출될 수 있는 $\mathrm{pH}$ 의존성 매트릭스 정제 개발이 가능하다 는 것도 알 수 있었다. 식품에서는 프탈레이트(phthalate) 기재에 대해 엄격한 규제가 이루어져 왔으나, 생리 활성 물질의 생체 이용률을 높이고, 위산 분해 시의 문제점 등 을 해결하기 위해 사용되는 장용성 코팅 제제에 대한 중 요성과 관심이 높아짐에 의해 법개정을 통해 장용성 코팅
기제의 경우에 한해 약사법에 근거하여 공정서에 수재되 어 있는 기제를 사용할 수 있도록 규제가 완화되었다. 비 록 규제완화에 의해 프탈레이트계의 장용성 코팅기제 사 용이 가능하다고는 하더라고 여전히 프탈레이트 안전에 대한 소비자들의 우려는 여전히 남아있으며, 이를 대체할 수 있는 장용성 코팅기제의 개발과 이를 응용한 장용성 제제 개발에 대한 연구가 절실한 상황이었으나 그 연구가 본격적으로 진행된 경우는 없었다. 본 기술을 사용하면 통 상적으로 경질캡슐제로 유통되는 제품보다 제형의 다양성 을 확보할 수 있을 뿐 아니라 또한 장용성 캡슐 제제에 비해 정제 제형으로 개발됨에 따라 제조원가 절감 및 생 산수율 향상을 기대할 수 있어 산업화에 바로 적용이 가 능하며 특히 프탈레이트를 사용하지 않고도 유산균 제제 의 제조가 가능하여 환경 보호의 측면에서도 많은 기여 를 할 수 있을 것으로 사료된다.

\section{Conflict of interest}

The authors declare that they have no conflict of interest.

\section{REFERENCES}

Abdel NZ, Aiman Q. Development and stability evaluation of enteric coated diclofenac sodium tablets using sureteric. J Pharm Sci. 2012. 25: 59-64.

Berrada N, Lemeland JF, Laroche G, Thouvenot P, Piaia M. Bifidobacterium from fer-mented milks: survival during gastric transit. J Dairy Sci. 1991. 74: 409-413.

Bouhnik Y, Pochart P, Marteau P, Arlet G, Goderel I, Rambaud JC. Faecal recovery in humans of viable Bifidobacterium sp. ingested in fermented milk. Gastroenterology. 1992. 102: 875 -878 .

Cross ML. Immunoregulation by probiotic lactobacilli: pro-Th1 signals and their relevance to human health. Clin Appl Immunol Rev. 2002. 3: 115-125.

Cui Yu, Kim SS, Park ES, Chi SC. Formulation of sustainedrelease matrix tablets of nifedipine. Journal of Pharmaceutical Investigation. 2002. 32: 95-101.

De Moreno de LeBlanc A, Chaves S, Carmuega E, Weill R, Antóine J, Perdigón G. Effect of long-term continuous consumption of fermented milk containing probiotic bacteria on mucosal immunity and the activity of peritoneal macrophages. Immunobiology. 2008. 213: 97-108.

Doh ST, Kim SH, Lee DY, Kwon OJ. The characteristics of 
pulverized powder by automatic tablet crusher. J Biomed Lab Sci. 2002. 8: 101-106.

Ferreira V, Soares V, Santos C, Silva J, Gibbs PA, Teixeira P. Survival of Lactobacillus sakei during heating, drying and storage in the dried state when growth has occurred in the presence of sucrose or monosodium glutamate. Biotechnol Lett. 2005. 27: 259-262.

Fuller R. Probiotics in human medicine. Gut. 1991. 32: 439-442.

Hong SB, Lee CH. Antimicrobial activity of Houttuynia cordata ethanol extract against major clinical resistant microorganisms. Korean J Clin Lab Sci. 2015. 47: 140-146.

Hong JH, Kim JY, Baek SE, Ingkasupart P, Park HJ, Kang SG. Effects of rice bran extracts fermented with Lactobacillus plantarum on neuroprotection and cognitive improvement in a rat model of ischemic brain Injury. Biomed Sci Lett. 2015. 21: 92-102.

Hove H, Norgaard H, Mortensen PB. Lactic acid bacteria and the human gastrointestinal tract. Eur J Clin Nutr. 1999. 53: 339 -350 .

Kim HH, Hong JH, Ingkasupart P, Lee DH, Yeo DN, Park HJ. Water extract from rice bran fermented with Lactobacillus plantarum Hong inhibits thromboxane $\mathrm{A}_{2}$ production associated microsomal enzyme activity in human platelets. Biomed Sci Lett. 2015. 21: 188-197.

Kim HS, Gilliland SE. Lactobacillus acidophilus as a dietary adjunct for milk to aid lactose digestion in humans. J Dairy Sci. 1983. 66: 959-966.

Korean Food and Drug Administration. Health functional food revolution. Korean Food and Drug Administration. 2011.

Marteau P, Pochart P, Bouhnik Y. Fate and effects of some transiting microorganisms in the human gastrointestinal tract. World Rev Nutr Diet. 1993. 74: 1-21.

McFarland LV, Surawicz CM, Greenberg RN, Elmer GW, Moyer KA, Melcher SA, Bowen KE, Cox JL. Prevention of betalactam-associated diarrhoea by Saccharomyces boulardii compared with placebo. Am J Gastroenterol. 1995. 90: 439-448.

Nguyen TDT, Kang JH, Lee MS. Characterization of Lactobacillus plantarum $\mathrm{PH} 04$, a potential probiotic bacterium with cholesterol-lowering effects. Eur J Clin Nutr. 2007. 113: 358-361.

Peck LT, Hamed M, Shuhaimi M, Anis SMH. Recent approaches in the development of encapsulated delivery systems for probiotics. Food Biotechnology. 2011. 25: 77-101. 